\title{
Ocean Energy - A Clean Renewable Energy Source
}

\author{
Phuoc Quy Phong Nguyen, Van Huong Dong
}

\begin{abstract}
The world is constantly seeking new sources of energy to replace the use of coal and fossil fuels to generate electricity. And a strong source of energy from the ocean is one of the hopes of scientists around the world. Ocean energy is an endless renewable energy source for making electricity used for the world. The ocean can produce two types of energy, thermal energy from the sun's heat and mechanical energy from tides and waves. Wave and tides power, the two main forms of harnessing energy from the ocean, are likely to grow significantly in the future, in terms of both installed capacity and investments. This paper presents an overview of applicability and new techniques for wave energy and tides.
\end{abstract}

Index Terms - Renewable Energy; Ocean Energy; Wave Energy; Tidal energy.

\section{INTRODUCTION}

In modern life, the quality of human life depends very much on energy resources, so the exploitation and use of energy are particularly concerned by countries. Traditional sources of energy such as fossil fuels, hydropower and nuclear power have met most of the needs of nations, but the use of these energy sources has certain limitations. Fossil energy is not renewable and at the current rate of use, scientists predict that in about 70 years the fuel will be depleted. We know that crude oil, natural gas and coal are all fossil fuels and that "Fossil fuel" is the general expression used to describe any type of "hydrocarbon" material that can be burnt or used as a fuel releasing its energy as heat [1]. They are called hydrocarbons because their chemical structure is based on a combination of hydrogen and carbon atoms. Under extreme heat and pressure, these atoms bond together and create long chains of molecules made up of hydrogen atoms attached to a backbone of carbon atoms. Once formed, hydrocarbons can exist in an almost infinite number of combinations, each with its own unique properties from a solid to a gas [2].

There are many uses for oil and sooner or later these underground oil reservoirs will be completely exhausted. Although it is estimated that there is enough crude oil left for about the next 40 to 50 years within the Earth's crust at the present pace of consumption, eventually the cost to recover those last few drops of oil deep within the Earth's crust will be beyond the value of the oil itself [3]. This is because crude oil is a thick, black liquid hydrocarbon that is pumped from underground up a narrow pipe to the Earth's surface it must first be refined before we can use it as a fuel for our cars or for heating.

Although oil has a high net energy yield and can be very helpful to us in many different ways, it can also be very

Published on January 8, 2019

P. Q. P. Nguyen, and V. H. Dong are with Ho Chi Minh city University of Transport, Ho Chi Minh city, Vietnam. harmful. One of the major problems associated with oil is the air pollution that it creates when burned [4]. Oil is one of the major causes of smog which is a type of air pollution [5]. Smog is created when oils are burned in places like power plants, industrial plants, and cars, releasing toxins [6] such as carbon dioxide into the atmosphere and which itself is classed as a type of harmful greenhouse gas [7]. Also oil pollution in the oceans and seas from oil leaking from our cars and other machinery which can then washed into the ocean through drains or oil spills from ships [8]-[10], oil tankers and oil rigs directly into the seas, can cause tremendous harm to ocean life[11]-[13].

According to the latest IEA data, the world fossil energy consumption in 2015 still accounts for $81.4 \%$ (the rest is new energy or renewable energy). In 1973, this proportion was $86.7 \%$ (of which oil alone accounted for $46.2 \%$ ). So after 42 years, the world only reduced $5.3 \%$ of fossil energy consumption thanks to the slight growth of clean energy. It should be noted that global natural gas production tripled and coal doubled since 1973. Global $\mathrm{CO}_{2}$ emissions derived from fuel combustion have doubled during this period. Under the Paris Agreement, to limit global warming by $2^{\circ} \mathrm{C}$ by 2100 , global emissions must be reduced from $40 \%$ to $70 \%$ by 2050 (compared to 2010 levels).

Biomass is available in all three basic forms of matter: Solid, Liquid, and Gas, which themselves can be subdivided into primary (produced by direct use of solar energy through photosynthesis) and secondary (generated by the decomposition or conversion of organic substances) products. Liquid Conversion of Biomass - another exciting alternative energy is the production of biomass fuels called Biofuel [14]. Biofuel is liquid fuel made from biomass, usually from plant matter. There are many types of biofuel with some common ones including methanol and ethanol, as well as synthetic gasoline, biodiesel, and aviation fuels. Ethanol is a major biofuel alternative to gasoline. Standard internal combustion engines can use a mixture of up to $10 \%$ ethanol. If it is an engine that improves fuel use in biology, this ratio may be much higher. Ethanol is produced using the enzyme of some types of yeast along with sugar making biomass [15]. Ethanol has a number of notable properties: when it burns, it only produces carbon dioxide that has been previously absorbed, thus reducing greenhouse gas emissions by $90 \%$ compared to petroleum-based fuels, it can be produced domestically or purchased in foreign markets at low prices and tested technology. Although proven to be good for cars, ethanol cannot replace JP-8 because its energy density is low; moreover, the disadvantage of this fuel is its high corrosion. The biodiesel is produced by the conversion of "ester", with the main materials being rapeseed and soybean, in addition to using hemp, mustard, palm oil, animal fat and oil taken from waste plants. With current technology, biodiesel can be produced to mix into 
gasoline at a rate of up to $5 \%$ without harming the engine [16]. In addition, this fuel has some limited properties, because its freezing point is nearly $0^{\circ} \mathrm{C}$ so it is more freeze than other fuels, so the viscosity increases and can cause harmful effects such as clogging the engine's filter. However, this problem can be overcome by increasing the ratio of bio-diesel to diesel oil to about $20 \%$. Water produced during biodiesel production also condenses when fuel is stored and may be a corrosive agent for engine parts [14],[17].

Current biotechnology has found new solutions. It is producing biofuels from microalgae's biomass. Biomass and lipid content in cells of microalgae are considered as "potential sources" for biofuel production, because of their high photosynthetic capacity, large biomass production and rapid growth. more than the crops used in the previous bioenergy industry. On the other hand, microalgae have the ability to use $\mathrm{CO}_{2}$ in metabolic processes, thus contributing to reducing the greenhouse effect. Moreover, microalgae can be used to produce high value compounds such as carbohydrates, hydrocarbons and natural oils. Therefore, microalgae are considered as a potential material source for biodiesel production, and can completely replace fossil diesel in the future. The idea of using microalgae as fuel sources is seriously recognized by scientists due to the increase in world oil prices, fossil fuel sources in nature are gradually depleted and more important is global warming related to burning fossil fuels [18].

Most people use the terms "alternative energy", "renewable energy" and even "green energy" together in the same sentence when taking about energy sources as though they all mean the same thing, but they are not the same. Each term means something different when talking about various types of energy systems [19]. For example, when we talk about alternative energy we think of wind turbines and solar panels. Renewable energy technologies use these devices to convert the wind and sunlight into usable forms of energy with zero emissions [2],[20]-[28].

The ocean is an endless renewable energy source for making electricity used for the world. In general, the theory of potential energy assessment of the ocean can reach $100,000 \mathrm{TWh} /$ year (while the world electricity consumption is $16,000 \mathrm{TWh} /$ year) [26]. In recent years the world has been widely interested in the energy of ocean waves. Exploiting the ocean to produce electricity from the vast ocean wave in the world's oceans is a solution to our energy problem. The transition to ocean wave resources alone can provide a huge portion of the power requirements of many European countries such as Northern Ireland, Denmark, Portugal, Spain and other countries. The US Institute of Electrical Energy Research has calculated the electrical wave energy along the coast of U.S [27]. can produce about 2,100 TWh / year. That output accounts for half of US electricity demand. In the UK, experts estimate that seawater can guarantee them up to $25 \%$ of their energy needs [22],[29]-[32].

Although there are still many unknowns about the effects of large and tidal wave exploitation systems on marine ecosystems, there are still many opinions that potential benefits are not to be missed. More than 800 times heavier than air, strong flowing water has the ability to exert very strong force [34]-[36]. Like the sun and wind, energy from the fluctuations of the ocean is free and clean. But ocean energy is more predictable than solar or wind because waves begin to form thousands of miles away from the coast and take days to peak, while tides depend on cycles. of the moon. Predictability makes it easier to balance supply and demand.

Marine technology was once considered too expensive to be a viable source of alternative clean energy, especially compared to already developed products such as wind and solar [24]. However, with the increased price of oil and the issues of global warming and national security, U.S. coastal sites are looking to add ocean energy to their renewable energy portfolios. This paper gives an overview of ocean energy technologies, focusing on four different types: wave, tidal, marine current, and ocean thermal energy conversion (OTEC) [25]. It outlines the operating principles, the status, and the efficiency and cost of generating energy associated with each technology.

The development of ocean energy projects is carried out in Europe and America. In Europe, ocean wave electrical devices have been tested since 60 s of the last century. In Spain in the years 2011-2020, the Renewable Energy Planning Institute boldly invested to research and develop relatively strong wave energy, has implemented many projects. It is calculated that in Spain it is possible to ensure that $42.3 \%$ of energy consumption is renewable energy by 2020 [28]. There are many technologies available to turn ocean wave energy into electricity and it is still unknown today [22].

Although we know that projects that exploit energy from the ocean will be very expensive, we believe that with the accumulated experience and production scale raised, the price will be lower and the technology will be improved to Hydrodynamic energy becomes an alternative energy source. In addition, the future taxation of carbon dioxide will reduce the price difference as well as raise the level of support for green energy [29].

Renewable energy or renewable energy is the energy from continuous sources that, according to human standards, are as limitless as solar, wind, rain, tide, waves and geothermal [20]. The basic principle of using renewable energy is to extract part of the energy from continuous processes in the environment and put it into technical uses. These processes are often promoted especially from the Sun. Renewable energy replaces traditional fuel sources in four areas: power generation, hot water heating, engine fuel, and rural independent power systems [2],[31].

Non-renewable energy sources such as coal, oil and gas are gradually exhausted and become scarce. Scientists are in the process of researching new energy sources, including the estimated total sea energy of 152.8 billion $\mathrm{kW}$ [42]. This type of energy is hundreds of times larger than the energy that all animals and plants need to grow on earth.

Sea waves are a potential source of energy, which can be developed and widely used in the renewable energy industry. The system of ocean wave energy exploitation is located deep in the sea, where fixed turbines or floating buoys will be difficult to operate effectively. Therefore, the turbines should be connected to cylindrical floating buoys and placed under the seabed with gravity anchors [21],[30]. 
Water pressure is 832 times greater than air pressure, so the movement of water will produce much more energy than wind power. To install a system to produce energy from the tide does not need to spend too much money and the cost to maintain is very low [48]. The tide is always active every year, this is a renewable energy source that brings the highest efficiency and especially with the lowest cost [39].

\section{WAVE ENERGY}

Waves and tides are used to rotate power generation turbines. The power produced can be used directly for marine equipment such as lighthouse, buoy, jetty, navigational system, etc.

Utilizing tidal energy sources is really a turning point in clean energy production, not polluting the environment [32]. The Norwegians have connected their national electricity grid with electricity from the first water turbine, whose energy is generated by rotors turned by sea currents. It is expected that by the end of the first years of the $21 \mathrm{st}$ century, they will complete construction of the next 20 factories. The Norwegian power plant has the advantage that no renewable energy source is available that is completely independent of the weather. Despite the situation, wind or wind, sun or rain ... tidal currents are still unaffected and the current generated still has a constant capacity [26]. The British also have similar investment plans. Although the idea of building a tidal power plant is not new, the Norwegian method of exploitation is very creative. This type of technological equipment was firstly built and installed in the river mouth by the French since 1967. That project is still active and has a capacity of $240 \mathrm{MW}$. The same pilot plants also appear in China, India, Canada and the Russian Federation.

Recently, turbines with a much larger capacity (300 kw) were first connected to the national electricity network. The impeller in the bottom of the water is fixed to the sea floor. Works at the Kvalsund Strait, near the Norwegian coastal city Hammerfest. Equipment with a tonnage of 200 tons. Norway intends to install 20 such turbines, ensuring the electricity supply to the town of 1.1 thousand people. The cost of construction is about 50 million Norwegian crowns (US \$ 20 million) [25].

The principle of operation of power plants using harnessed seawater is the same as traditional hydropower plants (Fig. 1): At first the water is filled with special "containers", spinning the turbine to generate electricity, then The water from the container escapes back to the ocean. On H.1, the Pelamis system collects energy from ocean waves [37].

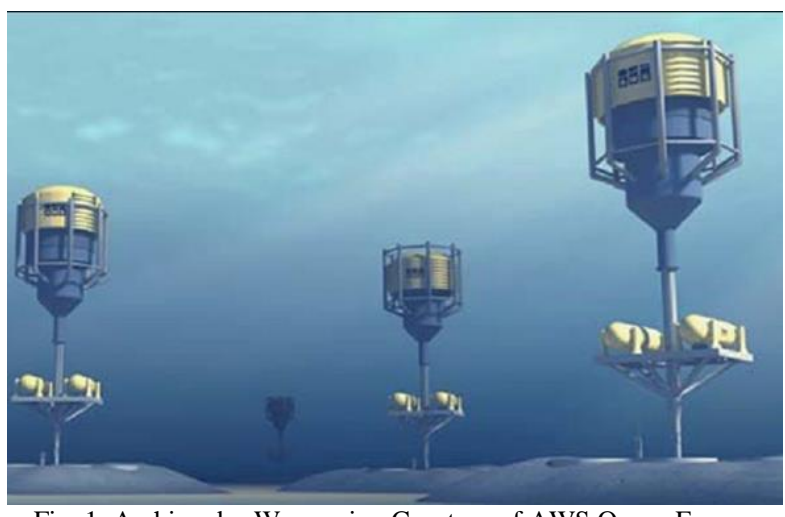

Fig. 1. Archimedes Waveswing Courtesy of AWS Ocean Energy

Besides the strong side that is not polluting the environment, power plants that use sea energy are still inevitable. Similar to the case of river dams, this type of power plant also creates an insurmountable barrier to seafood and makes it difficult for waterway traffic. Because of that reason, the French Government temporarily halted the plan to build the next 20 works. According to gender estimates opposed to construction, for example - only one dam on the Rhine also upset the marine environment within a radius of $500 \mathrm{~km}$ (Fig. 2) [37].

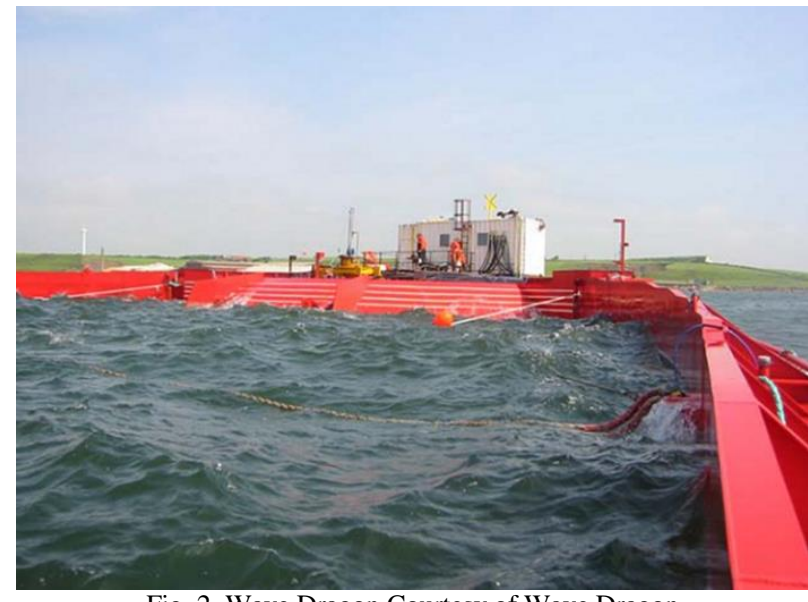

Fig. 2. Wave Dragon Courtesy of Wave Dragon

Besides the strong side that is not polluting the environment, power plants that use sea energy are still inevitable. Similar to the case of river dams, this type of power plant also creates an insurmountable barrier to seafood and makes it difficult for waterway traffic. Because of that reason, the French Government temporarily halted the plan to build the next 20 works. According to gender estimates opposed to construction, for example - only one dam on the Rhine also upset the marine environment within a radius of $500 \mathrm{~km} \mathrm{[38].}$

Wave energy is a concentrated form of solar energy. It is generated by the action of wind blowing over the surface of seawater, which can be used as a renewable energy source. When the sun rays hit the Earth's atmosphere, they warmed it up. The difference in the temperature of the air mass worldwide causes air to travel from hotter regions to colder regions, creating wind.

When the wind passes through the ocean surface, some of the wind's kinetic energy is transmitted to the water surface, creating waves. We can say that "Wave energy" is a form of wind energy indirectly causing the movement of water on 
the ocean surface. By collecting wind energy, the wave motion is converted into mechanical energy and used to run the generator. In many respects, the technology used to capture this wave energy is similar to tidal or hydroelectric energy [36].

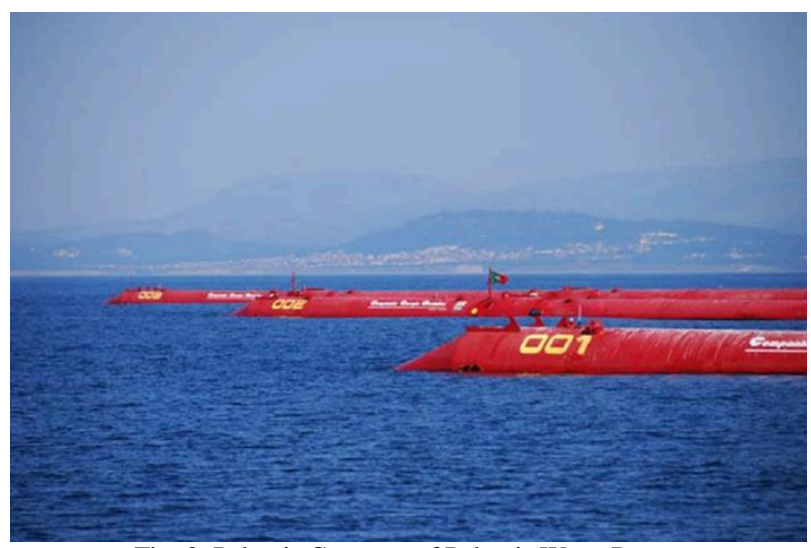

Fig. 3. Pelamis Courtesy of Pelamis Wave Power

Wave energy device is a module. Easily combined with additional wave energy devices added as needed.

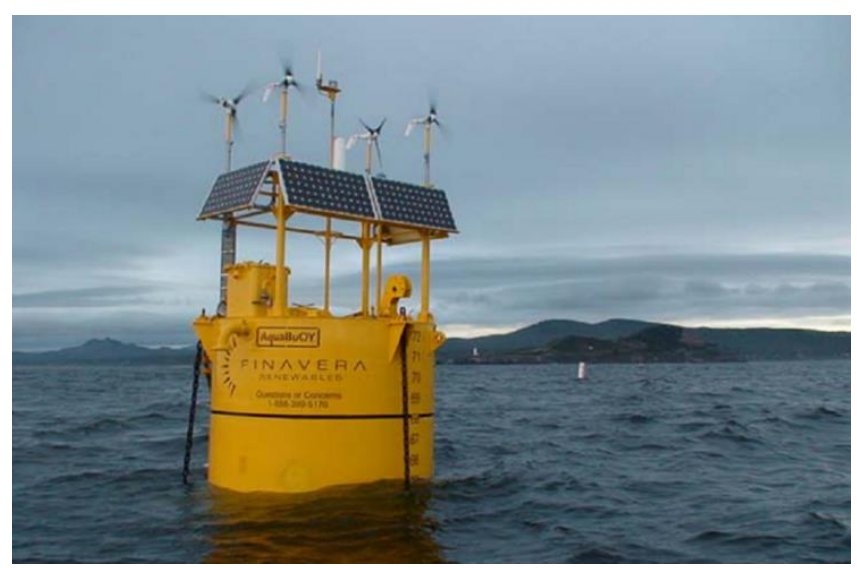

Fig. 4. AquaBuoy Courtesy of Finavera Renewables

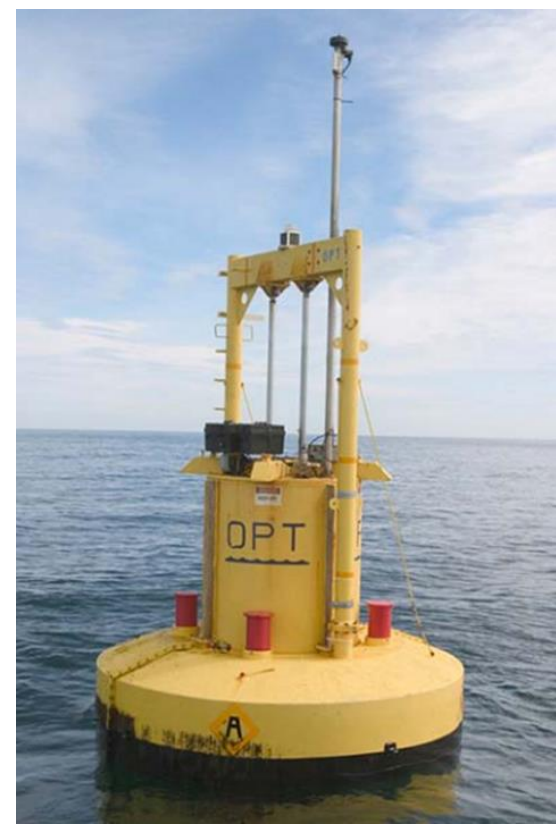

Fig. 5. PowerBuoy Courtesy of Ocean Power Technologies

Although Pelamis has beaten all companies out of the commercial door, OPT is still actively pursuing, with plans to install generators according to the first commercial scale buoy system in the North America next year (Fig. 4). This system - covering an area of about 1 square mile and like many other power systems, will be installed away from the traffic lanes of the ship - capable of producing about 2 megawatts of electricity. In September 2008, OPT also announced an agreement to install a 1.4-megawatt mining system off Spain. Another Australian subsidiary also agreed to a joint venture to develop a 10-megawatt electric mining system off the coast of Australia (Fig. 5).

Wave energy is considered a non-polluting and renewable energy source. Especially related to toxic emissions during operation. Wave energy devices do not generate pollutants and greenhouse gas emissions such as carbon dioxide and nitrous oxide related to burning fossil fuels to generate electricity [37]. Stationary wave energy conversion devices use pressure fluctuations produced in long tubes from the waves swelling up and down. This bobbing motion drives a turbine when critical pressure is reached. Other stationary platforms capture water from waves on their platforms. This water is allowed to runoff through narrow pipes that flow through a typical hydraulic turbine. Wave energy is proving to be the most commercially advanced of the ocean energy technologies with a number of companies competing for the lead [38].

However, almost all forms of electricity generation, whether renewable or conventional, will affect the environment in some form or shape, but it is often assumed that wave energy, which is an Clean can be self-replenishing for a short time, less environmental degradation than some other forms of renewable electricity generation [21].

\section{TIDAL ENERGY}

It was not until the 90s of the last century that a method of utilizing the tidal energy was the cleanest way: the "millers" under the water, they turned by moving sea currents. first installed in the Loch Lihne area, in Scotland, in 1995. It was tied to the anchor at the bottom of the sea and created only a power source of $15 \mathrm{Kw}$ [39].

Tidal or electric tidal energy is the amount of electricity obtained from the energy contained in the water movement by the tides. Currently, some parts of the world have deployed a system of generators using tidal energy [40].

In order to obtain energy from waves, the method of water column oscillation is used. The waves flowed into the coast, pushing the water level up in a large room built inside the coastal strip, partially submerged under the sea. When the water rises, the air inside the room is pushed out by a hole into a turbine. When the wave recedes, the water level drops inside the room to suck air through the turbine in the opposite direction. The rotating turbine makes a generator to produce electricity [41].

Producing tidal power or tidal energy is a way to turn tidal energy into electricity or other useful energy. In order to obtain energy from waves, the method of water column oscillation is used. The waves hit the coast, pushing the water level up in a large room built inside the coastal strip, partially submerged under the sea. When the water rises, the air inside the room is pushed out by a hole into a turbine. 
When the wave recedes, the water level drops, inside the room, it draws air through the turbine in the opposite direction (Fig. 6). The rotating turbine turns a transmitter to produce electricity. These turbines have wings that rotate in the same direction, regardless of the direction of air flow. But this new system also has its problems, the transmitters attached to seawater are corroded faster, the maintenance costs are quite high. Moreover, machines are large and bulky, which can interfere with waterway traffic and wild life. However, according to calculations by experts, the cost of producing tidal power is 0.1USD / kilowatt, higher than the price of hydroelectric and thermal power and equivalent to the cost of wind power motor [25]. However, unlike hydropower production, which may be interrupted by floods, tides can provide a stable source of energy. These values make tidal power generation the most appropriate form of electricity production for green growth. [42].

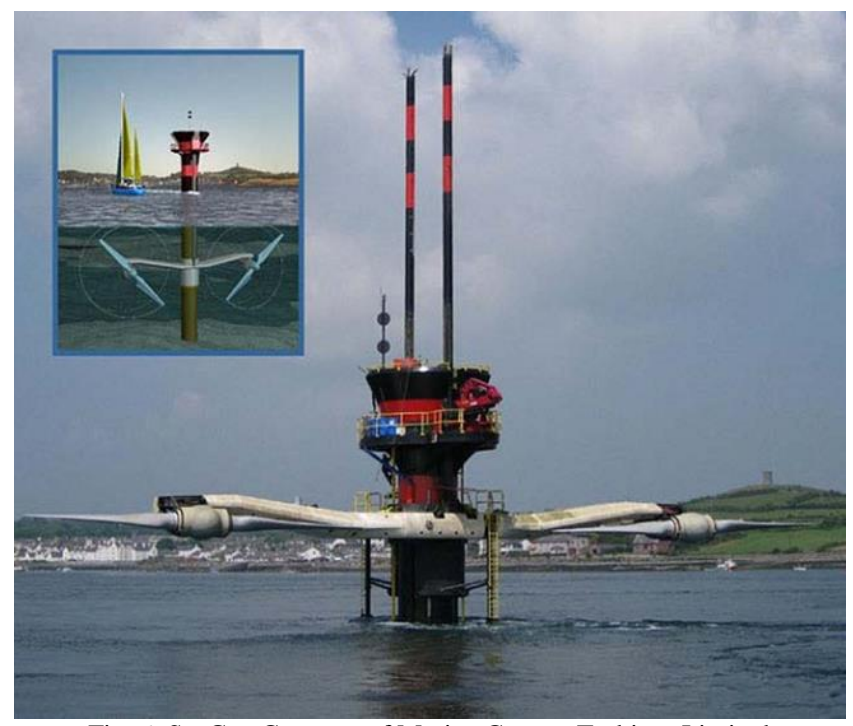

Fig. 6. SeaGen Courtesy of Marine Current Turbines Limited

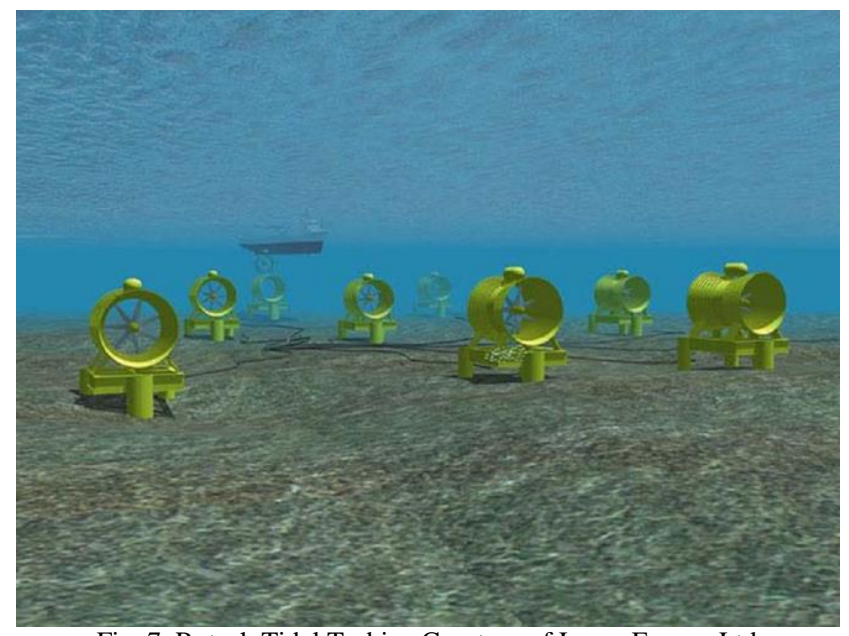

Fig. 7. Rotech Tidal Turbine Courtesy of Lunar Energy Ltd

Tidal energy is exploited by two ways, the tidal current kinetic energy turns the turbine to generate electricity and the dam prevents the potential energy between the high and low tide [43].

The first tidal power plant was built at the Rance River in France in 1966 with a 240 MW installed capacity of 24 turbines. With a $750 \mathrm{~m}$ long dam and $22.5 \mathrm{~km} 2$ tidal area, this is the world's largest tidal power plant (Fig. 7).
Sihwa Lake Tidal Power Plant, with a capacity of 254 MW in Korea, is under construction and is expected to be completed in 2011. Also there is an $812 \mathrm{MW}$ tidal dam project near Ganghwa Island, expected Northwest Northwest. completed in 2015 and the 1,320 MW tidal bar around Incheon western islands is expected to start in 2017 (Fig. 8).

The other tidal situation arises during neap tides (minimum) when the gravitational pull of the moon and the sun are against each other, thus cancelling their effects. The net result is a smaller pulling action on the sea water creating much smaller differences between the high and low tides thereby producing very weak tides. Neap tides occur during the quarter moon phase. Then spring tides and neap tides produce different amounts of potential energy in the movement of the sea water as their effects differ from the regular high and low sea levels and we can use these tidal changes to produce renewable energy. So we can say that the tides are turning for alternative energy.

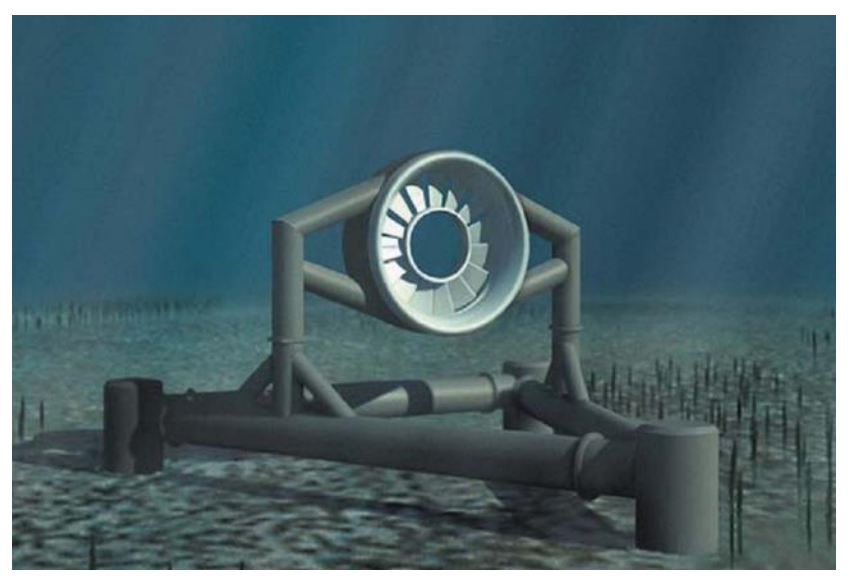

Fig. 8. Open-Centre Turbine Courtesy of OpenHydro

This turbine has wings that rotate in the same direction, regardless of the direction of the flow of air. But this new system also has its problems, the transmitters attached to seawater are corroded faster, the maintenance costs are quite high. Moreover, machines are large and bulky, which can interfere with waterway traffic and wild life. However, according to calculations by experts, the cost of producing tidal electricity is 0.1 USD / kilowatt, slightly higher than the price of gas and coal and equivalent to the cost of a wind power motor [44]-[55].

With advantages such as low cost, no harm to the environment, green energy sources such as solar, wind, especially power generation from tidal energy are considered as an alternative energy source. useful, being developed by many countries. Currently, La Rance Power Plant in France, with a capacity of $240,000 \mathrm{kWh}$, is one of the largest tidal power plants in the world.

Producing tidal power or tidal energy is a way to turn tidal energy into electricity or other useful energy. In order to obtain energy from waves, the method of water column oscillation is used. The waves hit the coast, pushing the water level up in a large room built inside the coastal strip, partially submerged under the sea. When the water rises, the air inside the room is ejected by a hole into a turbine. When the wave recedes, the water level falling inside the room will draw air through the turbine in the opposite direction. 
Turbine rotates as a generator to produce electricity[56][62].

The tidal current system reduces some environmental impacts by using turbine generators below the water surface. Large tidal currents and ocean currents can be exploited to release tidal energy using underwater propellers and turbines.

\section{CONCLUSION}

The benefits of hydrodynamic energy for the environment are quite clear: no carbon dioxide or any fossil fuel-related emissions. There is no oil spill incident, no radioactive waste. And for those individuals who object to the construction of the ocean-based system for aesthetic reasons, it will also be gratifying that the construction areas will not be visible from the mainland, the fan-type Windmills are designed to submerge underwater until they are brought up for maintenance.

Clean energy or renewable energy or renewable energy is the energy extracted from continuous and infinite sources such as solar, wind, rain, tide, waves. Basic principles for energy use This is the separation of a portion of energy from continuous processes in the environment by various technical means; The advantage of this energy source is clean, available in nature, no pollution, no exhaustion and the best solution to save fossil energy for the future.

The conclusion shows that tidal energy has a lot of potential to compete with other types of clean energy such as wind energy, solar energy, etc. The cost to operate tidal energy will be increasingly reduced thanks to goods. series of research as well as innovation.

However, towards ocean energy, the report shows that the development situation needs to be more focused to achieve price competition compared to other clean energy types.

\section{REFERENCES}

[1] A. T. Hoang and V. V Le, "Marine pollution and remedies of Vietnamese Government," Int. J. Recent Eng. Res. Dev, vol. 2, no. 4 pp. 51-55, 2017.

[2] A. T. Hoang and V. V. Pham, "A review on fuels used for marine diesel engines," J. Mech. Eng. Res. Dev. Res. Dev., vol. 41, no. 4, pp. 54-64, 2018

[3] V. V. Le and A. T. Hoang, "Fuel and alternative fuel for marine diesel engines," Int. J. Recent Eng. Res. Dev., vol. 2, no. 7, pp. 142-146, 2017.

[4] A. T. Hoang and A. T. Le, "A review on deposit formation in the injector of diesel engines running on biodiesel," Energy Sources, Part A Recover. Util. Environ. Eff., vol. 41, no. 05, pp. 584-599, 2018.

[5] A. T. Hoang, Q. V. Tran, and X. D. Pham, "Performance and Emission Characteristics of Popular 4-Stroke Motorcycle Engine in Vietnam Fuelled with Biogasoline Compared with Fossil Gasoline," Int. J. Mech. Mechatronics Eng., vol. 18, no. 02, pp. 97-103, 2018.

[6] A. T. Hoang and V. T. Nguyen, "Emission Characteristics of a Diesel Engine Fuelled with Preheated Vegetable Oil and Biodiesel," Philipp. J. Sci., vol. 146, no. 4, pp. 475-482, 2017.

[7] A. T. Hoang and V. V. Pham, "A study of emission characteristic, deposits, and lubrication oil degradation of a diesel engine running on preheated vegetable oil and diesel oil," Energy Sources, Part A Recover. Util. Environ. Eff., vol. 41, no. 05, pp. 611-625, 2018.

[8] H. Anh Tuan and C. Minh Quang, "A mini review of using oleophilic skimmers for oil spill recovery," J. Mech. Eng. Res. Dev., vol. 41, no. 2, pp. 92-96, 2018

[9] A. T. Hoang and X. D. Pham, "An investigation of remediation and recovery of oil spill and toxic heavy metal from maritime pollution by a new absorbent material," J. Mar. Eng. Technol., 2018.https://doi.org/10.1080/20464177.2018.1544401.

[10] A. T. Hoang, "A report of the oil spill recovery and treatment technologies to reduce the marine environment pollution," Int. J. $e$ Navigation Marit. Econ., vol. 9, pp. 35-49, 2018.

[11] T. N. Le, M. K. Pham, A. T. Hoang, T. N. M. Bui, and D. N. Nguyen, "Microstructure Change For Multi-Pass Welding Between Austenitic Stainless Steel And Carbon Steel,” J. Mech. Eng. Res. Dev., vol. 41, no. 2, pp. 97-102, 2018.

[12] M. K. Pham, D. N. Nguyen, and A. T. Hoang, "Influence of Vanadium Content on the Microstructure and Mechanical Properties of High-Manganese Steel,” Int. J. Mech. Mechatronics Eng., vol. 18, no. 2, pp. 141-147, 2018.

[13] M. T. Miglin, J. P. Hirth, A. R. Rosenfield, and W. A. T. Clark, "Microstructure of a quenched and tempered $\mathrm{Cu}$-bearing highstrength low-alloy steel," Metall. Trans. A, vol. 17, no. 5, pp. 791798, 1986.

[14] T. N. Le, M. K. Pham, A. T. Hoang, and D. N. Nguyen, "Microstructures and elements distribution in the transition zone of carbon steel and stainless steel welds," J. Mech. Eng. Res. Dev., vol. 41, no. 3, pp. 27-31, 2018.

[15] L. G. Korshunov, I. I. Kositsina, V. V Sagaradze, and N. L. Chernenko, "Effect of the carbide phase on the tribological properties of high-manganese antiferromagnetic austenitic steels alloyed with vanadium and molybdenum," Phys. Met. Metallogr., vol. 112, no. 1 , p. $90,2011$.

[16] X. D. Pham, A. T. Hoang, and D. N. Nguyen, "A Study on the Effect of the Change of Tempering Temperature on the Microstructure Transformation of Cu-Ni-Sn Alloy,” Int. J. Mech. Mechatronics Eng., vol. 18, no. 4, pp. 27-34, 2018.

[17] X. D. Pham, A. T. Hoang, D. N. Nguyen, and V. V Le, "Effect of Factors on the Hydrogen Composition in the Carburizing Process," Int. J. Appl. Eng. Res., vol. 12, no. 19, pp. 8238-8244, 2017.

[18] D. N. Nguyen, A. T. Hoang, M. T. Sai, M. Q. Chau, and V. V. Pham, "Effect of Sn component on properties and microstructure $\mathrm{Cu}-\mathrm{Ni}-\mathrm{Sn}$ alloys," J. Teknol., vol. 80, no. 6, pp. 43-51, 2018.

[19] A. T. Hoang, L. H. Nguyen, and D. N. Nguyen, "A Study of Mechanical Properties and Conductivity Capability of CU-9NI-3SN ALLOY," Int. J. Appl. Eng. Res., vol. 13, no. 7, pp. 5120-5126, 2018.

[20] A. T. Hoang, D. N. Nguyen, and V. V. Pham, "Heat Treatment Furnace For Improving The Weld Mechanical Properties: Design and Fabrication,” Int. J. Mech. Eng. Technol., vol. 9, no. 6, pp. 496-506, 2018.

[21] V. V. Pham, "Analyzing the effect of heated wall surface temperatures on combustion chamber deposit formation," J. Mech. Eng. Res. Dev., vol. 41, no. 4, pp. 17-21, 2018.

[22] A. T. Hoang et al., "An absorption capacity investigation of new absorbent based on polyurethane foams and rice straw for oil spill cleanup," Pet. Sci. Technol., vol. 36, no. 5, 2018.

[23] V. D. Tran, A. T. Le, V. H. Dong, and A. T. Hoang, "Methods of operating the marine engines by ultra-low sulfur fuel to aiming to satisfy MARPOLAnnex VI," Adv. Nat. Appl. Sci., vol. 11, no. 12, pp. 34-40, 2017.

[24] A. T. Hoang, "Prediction of the density and viscosity of biodiesel and the influence of biodiesel properties on a diesel engine fuel supply system," J. Mar. Eng. Technol. 2018.https://doi.org/10.1080/20464177.2018.1532734.

[25] A. T. Hoang, X. L. Bui, and X. D. Pham, "A novel investigation of oil and heavy metal adsorption capacity from as-fabricated adsorbent based on agricultural by-product and porous polymer," Energy Sources, Part A Recover. Util. Environ. Eff., vol. 40, no. 8, pp. 929939, 2018

[26] V. V. Le, D. C. Nguyen, and A. T. Hoang, "The potential of using the renewable energy aiming at environmental protection," Int. J. Latest Eng. Res. Appl., vol. 2, no. 7, pp. 54-60, 2017.

[27] A. T. Hoang, "Waste heat recovery from diesel engines based on Organic Rankine Cycle,” Appl. Energy, vol. 231, pp. 138-166, 2018.

[28] A. T. Hoang, Q. V. Tran, A. R. M. S. Al-Tawaha, V. V. Pham, and X. P. Nguyen, "Comparative analysis on performance and emission characteristics of an in-Vietnam popular 4-stroke motorcycle engine running on biogasoline and mineral gasoline," Renew. Energy Focus, vol. 28 , pp. 47-55, 2019.

[29] A. T. Hoang and D. N. Cao, "Some methods of reducing NOx components in exhaust gas," Int. J. Eng. Res. Manag. Stud., vol. 4, no. 5, pp. 11-18, 2017.

[30] M. T. Pham, A. T. Hoang, A. T. Le, A. R. M. S. Al-Tawaha, V. H. Dong, and V. V. Le, "Measurement and prediction of the density and viscosity of biodiesel blends," Int. J. Technol., vol. 9, no. 5, pp. 10151026, 2018.

[31] A. T. Hoang and M. T. Pham, "Influences of heating temperatures on physical properties, spray characteristics of bio-oils and fuel supply 
system of a conventional diesel engine," Int. J. Adv. Sci. Eng. Inf. Technol., vol. 8, no. 5, pp. 2231-2240, 2018.

[32] A. T. Hoang, "A Design and Fabrication of Heat Exchanger for Recovering Exhaust Gas Energy from Small Diesel Engine Fueled with Preheated Bio-oils," Int. J. Appl. Eng. Res., vol. 13, no. 7, pp. 5538-5545, 2018.

[33] A. T. Hoang, "The Performance of Diesel Engine Fueled Diesel Oil in Comparison with Heated Pure Vegetable Oils Available in Vietnam,' J. Sustain. Dev., vol. 10, no. 2, pp. 93-103, 2017.

[34] T. A. Hoang and V. Van Le, "The Performance of A Diesel Engine Fueled With Diesel Oil, Biodiesel and Preheated Coconut Oil," Int. J. Renew. Energy Dev., vol. 6, no. 1, pp. 1-7, 2017.

[35] A. T. Hoang, M. M. Noor, and X. D. Pham, "Comparative Analysis on Performance and Emission Characteristic of Diesel Engine Fueled with Heated Coconut Oil and Diesel Fuel," Int. J. Automot. Mech. Eng., vol. 15, no. 1, pp. 5110-5125, 2018.

[36] A. T. Hoang et al., "An absorption capacity investigation of new absorbent based on polyurethane foams and rice straw for oil spill cleanup," Pet. Sci. Technol., vol. 36, no. 5,pp. 361-370, 2018.

[37] R. Pelc and R. M. Fujita, "Renewable energy from the ocean," Mar. Policy, 2002.

[38] Ocean Energy Systems, “Annual Report Ocean Energy System 2015," 2015.

[39] C. E. Epifanio and R. W. Garvine, "Larval transport on the Atlantic Continental Shelf of North America: A review," Estuarine, Coastal and Shelf Science. 2001.

[40] Ocean Energy Forum, "Ocean energy strategic roadmap," Ocean Energy Strateg. Roadmap 2016, Build. Ocean energy Eur., 2016.

[41] A. S. Bahaj, "Generating electricity from the oceans," Renew. Sustain. Energy Rev., 2011.

[42] L. M. Brekhovskikh, V. V. Goncharov, K. A. Naugol'nykh, and S. A Rybak, "Waves in the ocean," Radiophys. Quantum Electron., 1976.

[43] W. Wang and R. X. Huang, "Wind Energy Input to the Surface Waves*," J. Phys. Oceanogr., 2004.

[44] European Ocean Energy Association, “Oceans of energy: European oceans energy roadmap 2010-2050," 2010

[45] L. H. Holthuijsen, Waves in oceanic and coastal waters. 2007.
[46] A. R. Plummer, A. J. Hillis, and C. Perez-Collazo, "Power systems," in Wave and Tidal Energy, 2017.

[47] P. L. Fraenkel, "Tidal current energy technologies," Ibis (Lond. 1859)., 2006.

[48] Tidal, "TIDAL," Tidal, 2016.

[49] K. J. Ptasinski, "Renewable Energy Resources,” Energy, 2015.

[50] I. G. Bryden and S. J. Couch, "ME1 - Marine energy extraction: Tidal resource analysis," in Renewable Energy, 2006.

[51] D. Greaves and G. Iglesias, Wave and tidal energy. 2017.

[52] IRENA(International Renewable Energy Agency), "Tidal energy technology brief," 2014

[53] T. A. Hoang, N. X. Chu, and T. Van Tran, "The Environmental Pollution In Vietnam: Source, Impact And Remedies," Int. J. Sci. Technol. Res., vol. 6, no. 2, pp. 249-253, 2017.

[54] N. Khan, A. Kalair, N. Abas, and A. Haider, "Review of ocean tidal, wave and thermal energy technologies," Renewable and Sustainable Energy Reviews. 2017.

[55] \{Sustainable Energy Ireland\} and \{Aea Energy \& Environment\}, "Review and analysis of ocean energy systems development and supporting policies," Renew. Energy, 2006.

[56] S. M. Masutani and P. K. Takahashi, "Ocean Thermal Energy Conversion (OTEC)," in Encyclopedia of Ocean Sciences, 2010.

[57] M. Ravindran and R. Abraham, "Ocean thermal energy conversion," in Springer Handbook of Ocean Engineering, 2016.

[58] M. Rhein et al., "Observations: Ocean," in Climate Change 2013 the Physical Science Basis: Working Group I Contribution to the Fifth Assessment Report of the Intergovernmental Panel on Climate Change, 2013.

[59] K. E. Trenberth, J. T. Fasullo, and M. A. Balmaseda, "Earth's energy imbalance," J. Clim., 2014

[60] C. Wunsch and R. Ferrari, "Vertical mixing, energy, and the general circulation of the oceans," Annu. Rev. Fluid Mech., 2004.

[61] J. Vining and A. Muetze, "Ocean Wave Energy Conversion," 2006.

[62] B. Drew, A. R. Plummer, and M. N. Sahinkaya, "A review of wave energy converter technology," Proceedings of the Institution of Mechanical Engineers, Part A: Journal of Power and Energy. 2009. 